ACCREDITATION COUNCIL FOR PHARMACY EDUCATION

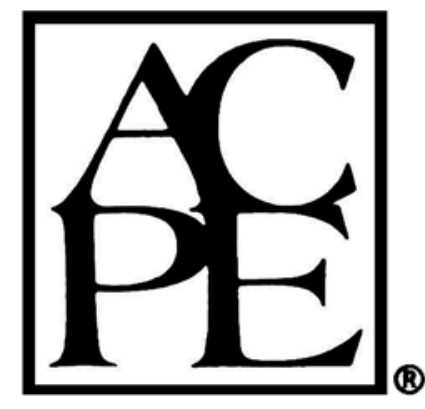

ACCREDITATION STANDARDS AND KEY ELEMENTS FOR THE PROFESSIONAL PROGRAM IN PHARMACY LEADING TO THE DOCTOR OF PHARMACY DEGREE

("STANDARDS 2016")

APPROVED January 25, 2015

RELEASED February 2, 2015

Accreditation Council for Pharmacy Education Chicago, Illinois

(c) 2015 


\section{TABLE OF CONTENTS}

PREAMBLE

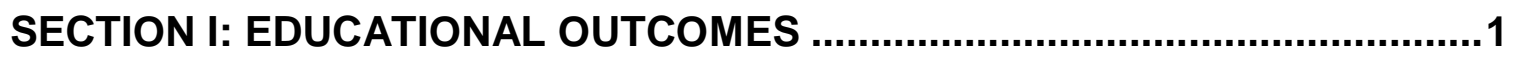

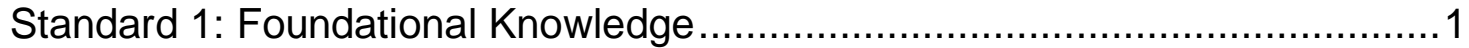

Standard 2: Essentials for Practice and Care .......................................... 1

Standard 3: Approach to Practice and Care ..............................................

Standard 4: Personal and Professional Development................................... 2

\section{SECTION II: STRUCTURE AND PROCESS TO PROMOTE}

ACHIEVEMENT OF EDUCATIONAL OUTCOMES........................................

Standard 5: Eligibility and Reporting Requirements...................................

Standard 6: College or School Vision, Mission, and Goals ............................ 3

Standard 7: Strategic Plan.................................................................. 4

Standard 8: Organization and Governance............................................ 4

Standard 9: Organizational Culture ........................................................ 5

Standard10: Curriculum Design, Delivery, and Oversight ............................. 5

Standard 11: Interprofessional Education (IPE) ......................................

Standard 12: Pre-Advanced Pharmacy Practice Experience

(Pre-APPE) Curriculum .......................................................... 8

Standard 13: Advanced Pharmacy Practice Experience (APPE) Curriculum ....9

Standard 14: Student Services ............................................................ 10

Standard 15: Academic Environment ….............................................. 10

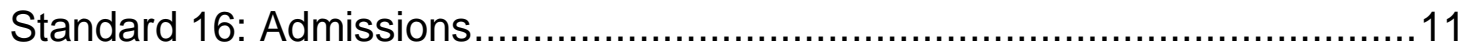

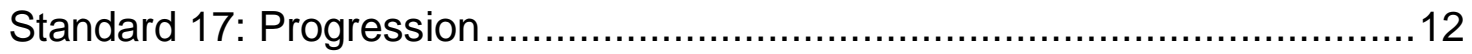

Standard 18: Faculty and Staff - Quantitative Factors ................................13

Standard 19: Faculty and Staff - Qualitative Factors.................................. 13

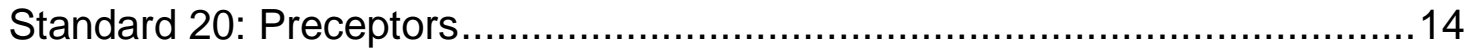

Standard 21: Physical Facilities and Educational Resources........................15

Standard 22: Practice Facilities ............................................................ 15

Standard 23: Financial Resources....................................................... 16

SECTION III: ASSESSMENT OF STANDARDS AND KEY ELEMENTS ...........17

Standard 24: Assessment Elements for Section I: Educational Outcomes .....17

Standard 25: Assessment Elements for Section II: Structure and Process .....17

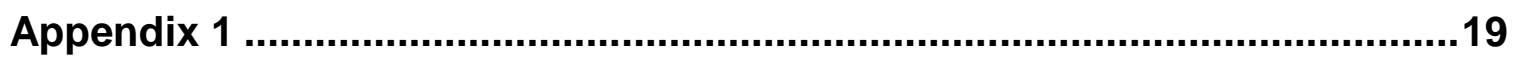

Required Elements of the Didactic Doctor of Pharmacy Curriculum 


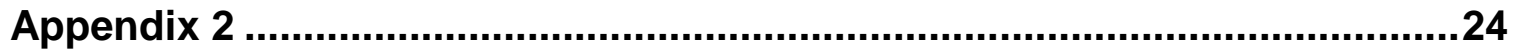

Expectations within the APPE Curriculum

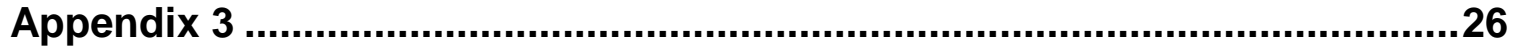

Required Documentation for Standards and Key Elements 2016 


\title{
ACCREDITATION COUNCIL FOR PHARMACY EDUCATION
}

\author{
STANDARDS 2016
}

PREAMBLE

\section{Accreditation Council for Pharmacy Education (ACPE)}

The Accreditation Council for Pharmacy Education (ACPE) is the national agency for the accreditation of professional degree programs in pharmacy and providers of continuing pharmacy education. ACPE (until 2003 known as the American Council on Pharmaceutical Education) was established in 1932 for the accreditation of professional degree programs in pharmacy, and in 1975 its scope was broadened to include accreditation of providers of continuing pharmacy education (www.acpe-accredit.org). ACPE expanded its activities to include evaluation and certification of professional degree programs internationally in 2011 and entered into a collaboration with the American Society of Health-System Pharmacists (ASHP) to accredit pharmacy technician education and training programs beginning in 2014. The mission of ACPE is to assure and advance quality in pharmacy education. ACPE is an autonomous and independent agency whose Board of Directors is appointed by the American Association of Colleges of Pharmacy (AACP), the American Pharmacists Association (APhA), the National Association of Boards of Pharmacy (NABP) (three appointments each), and the American Council on Education (ACE) (one appointment). Since the inception of its accreditation agency recognition program in 1952, the U.S. Department of Education (USDE) has continuously recognized ACPE. ACPE also gained recognition by the Council for Higher Education Accreditation (CHEA) in April 2004. State boards of pharmacy require that licensure applicants from the United States have graduated from an accredited pharmacy degree program to be eligible to sit for the North American Pharmacist Licensure Examination ${ }^{\mathrm{TM}}$ (NAPLEX®).

\section{Importance of Standards}

To achieve and maintain ACPE accreditation, professional Doctor of Pharmacy (PharmD) degree programs (hereafter described as 'programs') must meet the standards contained in this document. ACPE standards are minimum requirements, and it is expected that programs will exceed these required standards through initiatives designed to ensure continuous quality improvement. These standards describe the various elements needed for quality-assured professional education and are based on evidence and experience. They articulate expectations that ACPE (as well as pharmacy practice and the pharmacy academy) has of academic institutions offering the PharmD degree. ACPE standards also reflect the expectations that the U.S. Department of Education and state boards of pharmacy have of the colleges and schools, and of ACPE, regarding the quality of professional degree programs.

These standards have been developed with input from a broad range of constituents interested in and affected by pharmacy education. They focus on the educational outcomes required of PharmD programs and the assessment of those outcomes. They also address the structural and process-related elements within pharmacy education necessary to implement evidencebased outcome measures that document achievement of the standards. In addition, these standards describe areas where programs can experiment and innovate within the didactic and experiential components of their curricula to meet the required Educational Outcomes (Standards 1-4). Establishing a commitment to continuing professional development (CPD) by 
students and graduates is also addressed, as are contemporary educational concepts such student readiness to:

- $\quad$ Enter advanced pharmacy practice experiences (APPE-ready)

- Provide direct patient care in a variety of healthcare settings (Practice-ready)

- Contribute as a member of an interprofessional collaborative patient care team (Teamready)

\section{Revision of Standards: Background}

All accrediting bodies, including ACPE, periodically review and revise their standards. A number of environmental factors prompted ACPE to conduct a careful reassessment of the standards.

These factors included:

- The experience gained by ACPE in its accreditation reviews since the adoption of the Doctor of Pharmacy standards in 2007

- Feedback from ACPE stakeholders regarding quality improvement of the standards

- The reports of the Institute of Medicine (IOM) (www.iom.edu) noting needed changes in our healthcare system to improve medication safety and patient outcomes, including the five competencies that all healthcare professionals should attain during their education:

- Provide patient-centered care

- Work in interprofessional teams

- Employ evidence-based practice

- Apply quality improvement

- Utilize informatics

- Expansion of the scope of pharmacy practice in state laws and regulations to include collaborative practice with prescribers

- The revision of the AACP's Center for the Advancement of Pharmacy Education (CAPE) Educational Outcomes in 2013, which are intended to be the target toward which the evolving pharmacy curriculum should be aimed http://www.aacp.org/resources/education/cape/Pages/default.aspx

- The Joint Commission of Pharmacy Practitioners' (JCPP) Vision of Pharmacy Practice, accepted by the governing boards of 10 pharmacy organizations, including ACPE, and released in 2013 http://www.amcp.org/Tertiary.aspx?id=8463

- $\quad$ The document Pharmacists' Patient Care Process, developed by a work group from 11 national pharmacy organizations to promote a consistent approach to the process of care. This document was endorsed by the Joint Commission of Pharmacy Practitioners in 2014. http://www.pharmacist.com/sites/default/files/JCPP Pharmacists Patient Care Process.pdf

- Health Professionals for a New Century: Transforming education to strengthen health systems in an interdependent world http://www.thelancet.com/journals/lancet/article/PIIS0140-6736(10)61854-5/fulltext 
- Core Competencies for Interprofessional Collaborative Practice http://www.aacn.nche.edu/education-resources/ipecreport.pdf

- Revised NAPLEX Competency Statements http://www.nabp.net/programs/examination/naplex/naplex-blueprint

\section{Revision of Standards: Process Employed} In January 2012, ACPE announced to its stakeholders (including pharmacy colleges and schools, professional pharmacy organizations, student pharmacist organizations, and other accrediting bodies) its intent to revise the Doctor of Pharmacy degree standards. Written comments were solicited from stakeholders, and many were received. In addition, a Web-based survey that allowed anonymous completion was distributed to all the college or school of pharmacy deans. ACPE also held a multi-stakeholder invitational conference in fall, $2012^{1}$ to discuss issues facing pharmacy practice and education. The results of the conference influenced the direction and content of these revised standards. The first draft of the revised standards was approved by the ACPE Board of Directors in January 2014 and distributed to ACPE stakeholders in February 2014. Subsequently, a series of open hearings was conducted at national pharmacy meetings. Another Web-based survey that allowed anonymous completion by stakeholders was conducted during 2014, and an extensive review of the draft standards was completed by an advisory group from various sections of the academic and practice communities. The ACPE Board of Directors approved the revised standards on January 21-25, 2015 with an effective date of July 1, 2016. The new standards will be referred to as "Standards 2016." Colleges and schools being evaluated by ACPE beginning in the fall of 2016 must comply with the new standards.

\section{Revision of Standards: What's Different?}

- Format - The standards revision process yielded two distinct documents: Standards and Guidance. The Standards document includes the 25 standards, required (key) elements, assessment elements, and required documentation for each individual standard. The Guidance document was developed to support colleges' and schools' efforts to enhance the quality of their PharmD programs and includes suggested strategies, additional examples of compliance evidence, and other important information to facilitate meeting standards. ACPE expects programs to be in compliance with all elements outlined in the Standards document and to use the information within the Guidance document to improve the quality of their programs. In other words, the Standards document contains required elements that all accredited Doctor of Pharmacy programs must meet, while the Guidance document contains clarifying statements and suggested strategies for improvement.

- Philosophy and Emphasis - Based on stakeholder feedback, the Standards have been refined to ensure that graduating students are "practice-ready" and "team-ready," that is, prepared to directly contribute to patient care working in collaboration with other healthcare providers. The revision has also placed greater emphasis on critical educational outcomes identified by CAPE and the assessment of the level of student

\footnotetext{
${ }^{1}$ Zellmer WA, Vlasses PH, Beardsley RS. Summary of the ACPE Consensus Conference on Advancing Quality in Pharmacy Education. Am J Pharm Educ. 2013; 77, 3, Article 44.
} 
achievement of these outcomes. The Standards focus on the (1) development of students' professional knowledge, skills, abilities, behaviors, and attitudes, including scientific foundation, knowledge application, and practice competencies, (2) the manner in which programs assess students' acquisition of knowledge and application of knowledge to practice, (3) mastery of skills and achievement of competencies, and (4) the importance of both curricular and co-curricular experiences in advancing the professional development of students. Throughout the revision process, ACPE has focused on addressing the environmental factors noted above in Revision of Standards: Background.

- Importance of Assessment - Based on feedback from the academy and other stakeholders, the new Standards emphasize assessment as a means of improving the quality of pharmacy education. Having valid and reliable assessment mechanisms in place will provide additional insights to programs regarding their strengths and deficiencies. Throughout the Standards, terms such as "adequate," "sufficient," and "appropriate" appear in several areas. Programs are expected to utilize assessment outcome data to determine if the available resources are adequate, sufficient, etc. to allow for compliance with the Standards.

- Organization of Standards - Although, at a minimum, the Standards address the same critical areas as in previous versions, they have been restructured, simplified, and clarified. The Standards are organized into three major sections (Educational Outcomes; Structure and Process to Promote Achievement of Educational Outcomes; and Assessment). The Structure and Process section is further organized into four subsections: (1) Planning and Organization, (2) Educational Program for the Doctor of Pharmacy Degree, (3) Students, and (4) Resources. In the third section, Standards 24 and 25 list the assessment elements for Educational Outcomes and Structure and Process, respectively. Standards and Key Elements are phrased as declarative statements describing the various attributes of an accredited Doctor of Pharmacy program. Programs not meeting the expectations and requirements outlined within these statements will be out of compliance with the Standards. Standards annotated with an asterisk $\left(^{*}\right)$ are appropriate for new program initiatives and alternate pathways to degree completion, such as an accelerated curriculum, geographically dispersed campuses, online or distance-learning-based programs, and other educational innovations. Three appendices are included within the Standards. Appendix 1 is a revision of the former Appendix B in Standards 2007 and describes the required elements of the didactic component of the PharmD curriculum. Appendix 2 (formerly Appendix C in Standards 2007) describes the expectations of the experiential learning component of the curriculum. Appendix 3 outlines the documentation needed for the Standards and Key Elements.

- Organization of Guidance - Materials are provided in this document to help colleges and schools of pharmacy: (1) understand the breadth and scope of issues underlying the achievement of each standard and (2) achieve academic program enhancement. Suggested strategies for quality improvement are based on evidence gleaned from the literature and/or the evaluation of successful programs.

- Innovation - Colleges or schools may choose avenues other than those suggested in the guidance document to achieve compliance with the Standards. In all cases, however, ACPE requires evidence that standards are being met. 
- Style - The Chicago Manual of Style, $15^{\text {th }}$ Edition, Chicago: The University of Chicago Press, 2003, was used in the preparation of the standards and guidelines.

\section{Summary}

ACPE looks forward to working with colleges and schools of pharmacy during the transition to the revised professional degree program Standards. Through its strategic plan, ACPE will also be investigating opportunities for better and more standardized ways to evaluate the achievement of the Standards, including the identification of valid outcome measures to be monitored across all accredited programs. In addition, ACPE will be improving its policies and procedures to allow for greater standardization, consistency, efficiency, and effectiveness in its accreditation activities and evaluations. Feedback from ACPE stakeholders is always invited and valued.

ACPE Board of Directors and Staff January 25, 2015 


\section{STANDARDS AND KEY ELEMENTS \\ SECTION I: EDUCATIONAL OUTCOMES}

The educational outcomes ${ }^{2}$ described herein have been deemed essential to the contemporary practice of pharmacy in a healthcare environment that demands interprofessional collaboration and professional accountability for holistic patient well-being.

\section{Standard 1: Foundational Knowledge}

The professional program leading to the Doctor of Pharmacy degree (hereinafter "the program") develops in the graduate the knowledge, skills, abilities, behaviors, and attitudes necessary to apply the foundational sciences to the provision of patient-centered care.

\section{Key Element:}

1.1. Foundational knowledge - The graduate is able to develop, integrate, and apply knowledge from the foundational sciences (i.e., biomedical, pharmaceutical, social/behavioral/administrative, and clinical sciences) to evaluate the scientific literature, explain drug action, solve therapeutic problems, and advance population health and patient-centered care.

\section{Standard 2: Essentials for Practice and Care}

The program imparts to the graduate the knowledge, skills, abilities, behaviors, and attitudes necessary to provide patient-centered care, manage medication use systems, promote health and wellness, and describe the influence of population-based care on patient-centered care.

\section{Key Elements:}

2.1. Patient-centered care - The graduate is able to provide patient-centered care as the medication expert (collect and interpret evidence, prioritize, formulate assessments and recommendations, implement, monitor and adjust plans, and document activities).

2.2. Medication use systems management - The graduate is able to manage patient healthcare needs using human, financial, technological, and physical resources to optimize the safety and efficacy of medication use systems.

2.3. Health and wellness - The graduate is able to design prevention, intervention, and educational strategies for individuals and communities to manage chronic disease and improve health and wellness.

2.4. Population-based care - The graduate is able to describe how population-based care influences patient-centered care and the development of practice guidelines and evidence-based best practices.

\footnotetext{
${ }^{2}$ Adapted from the American Association of Colleges of Pharmacy's Center for the Advancement of Pharmacy Education (CAPE) Educational Outcomes, 2013.
} 


\section{Standard 3: Approach to Practice and Care}

The program imparts to the graduate the knowledge, skills, abilities, behaviors, and attitudes necessary to solve problems; educate, advocate, and collaborate, working with a broad range of people; recognize social determinants of health; and effectively communicate verbally and nonverbally.

\section{Key Elements:}

3.1. Problem solving - The graduate is able to identify problems; explore and prioritize potential strategies; and design, implement, and evaluate a viable solution.

3.2. Education - The graduate is able to educate all audiences by determining the most effective and enduring ways to impart information and assess learning.

3.3. Patient advocacy - The graduate is able to represent the patient's best interests.

3.4. Interprofessional collaboration - The graduate is able to actively participate and engage as a healthcare team member by demonstrating mutual respect, understanding, and values to meet patient care needs.

3.5. Cultural sensitivity - The graduate is able to recognize social determinants of health to diminish disparities and inequities in access to quality care.

3.6. Communication - The graduate is able to effectively communicate verbally and nonverbally when interacting with individuals, groups, and organizations.

\section{Standard 4: Personal and Professional Development}

The program imparts to the graduate the knowledge, skills, abilities, behaviors, and attitudes necessary to demonstrate self-awareness, leadership, innovation and entrepreneurship, and professionalism.

\section{Key Elements:}

4.1. Self-awareness - The graduate is able to examine and reflect on personal knowledge, skills, abilities, beliefs, biases, motivation, and emotions that could enhance or limit personal and professional growth.

4.2. Leadership - The graduate is able to demonstrate responsibility for creating and achieving shared goals, regardless of position.

4.3. Innovation and entrepreneurship - The graduate is able to engage in innovative activities by using creative thinking to envision better ways of accomplishing professional goals.

4.4. Professionalism - The graduate is able to exhibit behaviors and values that are consistent with the trust given to the profession by patients, other healthcare providers, and society. 


\section{SECTION II: STRUCTURE AND PROCESS TO PROMOTE ACHIEVEMENT OF EDUCATIONAL OUTCOMES}

The Educational Outcomes articulated in Section I can only be fully achieved in an academic culture purposely designed to nurture learners and to support the administrators, faculty, preceptors, and staff who mentor them. The standards in Section II describe essential structures and processes that provide the organizational stability and potential for advancement critical to continuous quality improvement in pharmacy education.

\section{Subsection IIA: Planning and Organization}

\section{Standard 5: Eligibility and Reporting Requirements}

The program meets all stated degree-granting eligibility and reporting requirements.

\section{Key Elements:}

5.1. Autonomy - The academic unit offering the Doctor of Pharmacy program is an autonomous unit organized as a college or school of pharmacy (within a university or as an independent entity). This includes autonomy to manage the professional program within stated policies and procedures, as well as applicable state and federal regulations.

5.2. Legal empowerment - The college or school is legally empowered to offer and award the Doctor of Pharmacy degree.

5.3. Dean's leadership - The college or school is led by a dean, who serves as the chief administrative and academic officer of the college or school and is responsible for ensuring that all accreditation requirements of ACPE are met.

5.4. Regional/institutional accreditation - The institution housing the college or school, or the independent college or school, has (or, in the case of new programs, is seeking) full accreditation by a regional/institutional accreditation agency recognized by the U.S. Department of Education.

5.5. Regional/institutional accreditation actions - The college or school reports to ACPE within 30 days any issue identified in regional/institutional accreditation actions that may have a negative impact on the quality of the professional degree program and compliance with ACPE standards.

5.6. Substantive change - The dean promptly reports substantive changes in organizational structure and/or processes (including financial factors) to ACPE for the purpose of evaluation of their impact on programmatic quality.

\section{Standard 6: College or School Vision, Mission, and Goals}

The college or school publishes statements of its vision, mission, and goals.

Key Elements:

6.1. College or school vision and mission - These statements are compatible with the vision and mission of the university in which the college or school operates. 
6.2. Commitment to educational outcomes - The mission statement is consistent with a commitment to the achievement of the Educational Outcomes (Standards 1-4).

6.3. Education, scholarship, service, and practice - The statements address the college or school's commitment to professional education, research and scholarship, professional and community service, pharmacy practice, and continuing professional development.

6.4. Consistency of initiatives - All program initiatives are consistent with the college or school's vision, mission, and goals.

6.5. Subunit goals and objectives alignment - If the college or school organizes its faculty into subunits, the subunit goals are aligned with those of the college or school.

\section{Standard 7: Strategic Plan}

The college or school develops, utilizes, assesses, and revises on an ongoing basis a strategic plan that includes tactics to advance its vision, mission, and goals.

\section{Key Elements:}

7.1. Inclusive process - The strategic plan is developed through an inclusive process, including faculty, staff, students, preceptors, practitioners, and other relevant constituents, and is disseminated in summary form to key stakeholders.

7.2. Appropriate resources - Elements within the strategic plan are appropriately resourced and have the support of the university administration as needed for implementation.

7.3. Substantive change planning - Substantive programmatic changes contemplated by the college or school are linked to its ongoing strategic planning process.

\section{Standard 8: Organization and Governance}

The college or school is organized and staffed to advance its vision and facilitate the accomplishment of its mission and goals.

\section{Key Elements:}

8.1. Leadership collaboration - University leadership and the college or school dean collaborate to advance the program's vision and mission and to meet ACPE accreditation standards. The dean has direct access to the university administrator(s) with ultimate responsibility for the program.

8.2. Qualified dean - The dean is qualified to provide leadership in pharmacy professional education and practice, research and scholarship, and professional and community service.

8.3. Qualified administrative team - The dean and other college or school administrative leaders have credentials and experience that have prepared them for their respective roles and collectively have the needed backgrounds to effectively manage the educational program. 
8.4. Dean's other substantial administrative responsibilities - If the dean is assigned other substantial administrative responsibilities, the university ensures adequate resources to support the effective administration of the affairs of the college or school.

8.5. Authority, collegiality, and resources - The college or school administration has defined lines of authority and responsibility, fosters organizational unit collegiality and effectiveness, and allocates resources appropriately.

8.6. College or school participation in university governance - College or school administrators and faculty are effectively represented in the governance of the university, in accordance with its policies and procedures.

8.7. Faculty participation in college or school governance - The college or school uses updated, published documents, such as bylaws, policies, and procedures, to ensure faculty participation in the governance of the college or school.

8.8. Systems failures - The college or school has comprehensive policies and procedures that address potential systems failures, including technical, administrative, and curricular failures.

8.9. Alternate pathway equitability* - The college or school ensures that any alternative pathways to the Doctor of Pharmacy degree are equitably resourced and integrated into the college or school's regular administrative structures, policies, and procedures, including planning, oversight, and evaluation.

\section{Standard 9: Organizational Culture}

The college or school provides an environment and culture that promotes self-directed lifelong learning, professional behavior, leadership, collegial relationships, and collaboration within and across academic units, disciplines, and professions.

\section{Key Elements:}

9.1. Leadership and professionalism - The college or school demonstrates a commitment to developing professionalism and to fostering leadership in administrators, faculty, preceptors, staff, and students. Faculty and preceptors serve as mentors and positive role models for students.

9.2. Behaviors - The college or school has policies that define expected behaviors for administrators, faculty, preceptors, staff, and students, along with consequences for deviation from those behaviors.

9.3. Culture of collaboration - The college or school develops and fosters a culture of collaboration within subunits of the college or school, as well as within and outside the university, to advance its vision, mission, and goals, and to support the profession.

\section{Subsection IIB: Educational Program for the Doctor of Pharmacy Degree}

\section{Standard 10: Curriculum Design, Delivery, and Oversight}

The curriculum is designed, delivered, and monitored by faculty to ensure breadth and depth of requisite knowledge and skills, the maturation of professional attitudes and behaviors, and the 
opportunity to explore professional areas of interest. The curriculum also emphasizes active learning pedagogy, content integration, knowledge acquisition, skill development, and the application of knowledge and skills to therapeutic decision-making.

\section{Key Elements:}

10.1. Program duration - The professional curriculum is a minimum of four academic years of full-time study or the equivalent.

10.2. Curricular oversight - Curricular oversight involves collaboration between faculty and administration. The body/bodies charged with curricular oversight: (1) are representative of the faculty at large, (2) include student representation, (3) effectively communicate and coordinate efforts with body/bodies responsible for curricular assessment, and (4) are adequately resourced to ensure and continually advance curricular quality.

10.3. Knowledge application - Curricular expectations build on a pre-professional foundation of scientific and liberal studies. The professional curriculum is organized to allow for the logical building of a sound scientific and clinical knowledge base that culminates in the demonstrated ability of learners to apply knowledge to practice.

10.4. Skill development - The curriculum is rigorous, contemporary, and intentionally sequenced to promote integration and reinforcement of content and the demonstration of competency in skills required to achieve the Educational Outcomes articulated in Section I.

10.5. Professional attitudes and behaviors development - The curriculum inculcates professional attitudes and behaviors leading to personal and professional maturity consistent with the Oath of the Pharmacist.

10.6. Faculty and preceptor credentials/expertise - All courses in the curriculum are taught by individuals with academic credentials and expertise that are explicitly linked to their teaching responsibilities.

10.7. Content breadth and depth - Programs document, through mapping or other comparable methods, the breadth and depth of exposure to curricular content areas deemed essential to pharmacy education at the doctoral level (Appendices 1 and 2).

10.8. Pharmacists' Patient Care Process - The curriculum prepares students to provide patient-centered collaborative care as described in the Pharmacists' Patient Care Process model endorsed by the Joint Commission of Pharmacy Practitioners.

10.9. Electives - Time is reserved within the core curriculum for elective didactic and experiential education courses that permit exploration of and/or advanced study in areas of professional interest.

10.10. Feedback - The curriculum allows for timely, formative performance feedback to students in both didactic and experiential education courses. Students are also provided the opportunity to give formative and/or summative feedback to faculty, including preceptors, on their perceptions of teaching/learning effectiveness. 
10.11. Curriculum review and quality assurance - Curriculum design, delivery, and sequencing are regularly reviewed and, when appropriate, revised by program faculty to ensure optimal achievement of educational outcomes with reasonable student workload expectations.

10.12. Teaching and learning methods - The didactic curriculum is delivered via teaching/learning methods that: (1) facilitate achievement of learning outcomes, (2) actively engage learners, (3) promote student responsibility for self-directed learning, (4) foster collaborative learning, and (5) are appropriate for the student population (i.e., campus-based vs. distance-based).

10.13. Diverse learners - The didactic curriculum incorporates teaching techniques and strategies that address the diverse learning needs of students.

10.14. Course syllabi - Syllabi for didactic and experiential education courses, developed and updated through a faculty-approved process, contain information that supports curricular quality assurance assessment.

10.15. Experiential quality assurance - A quality assurance procedure for all pharmacy practice experiences is established and implemented to: (1) facilitate achievement of stated course expectations, (2) standardize key components of experiences across all sites offering the same experiential course, and (3) promote consistent assessment of student performance.

10.16. Remuneration/employment - Students do not receive payment for participating in curricular pharmacy practice experiences, nor are they placed in the specific practice area within a pharmacy practice site where they are currently employed. ${ }^{3}$

10.17. Academic integrity* - To ensure the credibility of the degree awarded, the validity of individual student assessments, and the integrity of student work, the college or school ensures that assignments and examinations take place under circumstances that minimize opportunities for academic misconduct. The college or school ensures the correct identity of all students (including distance students) completing proctored assessments.

\section{Standard 11: Interprofessional Education (IPE)}

The curriculum prepares all students to provide entry-level, patient-centered care in a variety of practice settings as a contributing member of an interprofessional team. In the aggregate, team exposure includes prescribers as well as other healthcare professionals.

\section{Key Elements:}

11.1. Interprofessional team dynamics - All students demonstrate competence in interprofessional team dynamics, including articulating the values and ethics that underpin interprofessional practice, engaging in effective interprofessional communication, including conflict resolution and documentation skills, and honoring interprofessional roles and responsibilities. Interprofessional team dynamics are

\footnotetext{
${ }^{3}$ A professional degree program in an institution that meets the definition of and has an institution-wide commitment to "cooperative education" (Cooperative Education and Internship Association; http://www.ceiainc.org) may apply to ACPE for a waiver of this requirement.
} 
introduced, reinforced, and practiced in the didactic and Introductory Pharmacy Practice Experience (IPPE) components of the curriculum, and competency is demonstrated in Advanced Pharmacy Practice Experience (APPE) practice settings.

11.2. Interprofessional team education - To advance collaboration and quality of patient care, the didactic and experiential curricula include opportunities for students to learn about, from, and with other members of the interprofessional healthcare team. Through interprofessional education activities, students gain an understanding of the abilities, competencies, and scope of practice of team members. Some, but not all, of these educational activities may be simulations.

11.3. Interprofessional team practice - All students competently participate as a healthcare team member in providing direct patient care and engaging in shared therapeutic decision-making. They participate in experiential educational activities with prescribers/student prescribers and other student/professional healthcare team members, including face-to-face interactions that are designed to advance interprofessional team effectiveness

\section{Standard 12: Pre-Advanced Pharmacy Practice Experience (Pre-APPE) Curriculum}

The Pre-APPE curriculum provides a rigorous foundation in the biomedical, pharmaceutical, social/administrative/behavioral, and clinical sciences, incorporates Introductory Pharmacy Practice Experience (IPPE), and inculcates habits of self-directed lifelong learning to prepare students for Advanced Pharmacy Practice Experience (APPE).

\section{Key Elements:}

12.1. Didactic curriculum - The didactic portion of the Pre-APPE curriculum includes rigorous instruction in all sciences that define the profession (see Appendix 1).

Appropriate breadth and depth of instruction in these sciences is documented regardless of curricular model employed (e.g., blocked, integrated, traditional 'stand-alone' course structure, etc.).

12.2. Development and maturation - The Pre-APPE curriculum allows for the development and maturation of the knowledge, skills, abilities, attitudes, and behaviors that underpin the Educational Outcomes articulated in Standards 1-4 and within Appendices 1 and 2.

12.3. Affective domain elements - Curricular and, if needed, co-curricular activities and experiences are purposely developed and implemented to ensure an array of opportunities for students to document competency in the affective domain-related expectations of Standards 3 and 4. Co-curricular activities complement and advance the learning that occurs within the formal didactic and experiential curriculum.

12.4. Care across the lifespan - The Pre-APPE curriculum provides foundational knowledge and skills that allow for care across the patient's lifespan.

12.5. IPPE expectations - IPPEs expose students to common contemporary U.S. practice models, including interprofessional practice involving shared patient care decision-making, professional ethics and expected behaviors, and direct patient care activities. IPPEs are structured and sequenced to intentionally develop in students a 
clear understanding of what constitutes exemplary pharmacy practice in the U.S. prior to beginning APPE.

12.6. IPPE duration - IPPE totals no less than 300 clock hours of experience and is purposely integrated into the didactic curriculum. A minimum of 150 hours of IPPE are balanced between community and institutional health-system settings.

12.7. Simulation for IPPE - Simulated practice experiences (a maximum of 60 clock hours of the total 300 hours) may be used to mimic actual or realistic pharmacistdelivered patient care situations. However, simulation hours do not substitute for the 150 clock hours of required IPPE time in community and institutional health-system settings. Didactic instruction associated with the implementation of simulated practice experiences is not counted toward any portion of the 300 clock hour IPPE requirement.

\section{Standard 13: Advanced Pharmacy Practice Experience (APPE) Curriculum}

A continuum of required and elective APPEs is of the scope, intensity, and duration required to support the achievement of the Educational Outcomes articulated in Standards 1-4 and within Appendix 2 to prepare practice-ready graduates. APPEs integrate, apply, reinforce, and advance the knowledge, skills, attitudes, abilities, and behaviors developed in the Pre-APPE curriculum and in co-curricular activities.

\section{Key Elements:}

13.1. Patient care emphasis - Collectively, APPEs emphasize continuity of care and incorporate acute, chronic, and wellness-promoting patient-care services in outpatient (community/ambulatory care) and inpatient (hospital/health system) settings.

13.2. Diverse populations - In the aggregate, APPEs expose students to diverse patient populations as related to age, gender, race/ethnicity, socioeconomic factors (e.g., rural/urban, poverty/affluence), and disease states)

13.3. Interprofessional experiences - In the aggregate, students gain in-depth experience in delivering direct patient care as part of an interprofessional team.

13.4. APPE duration - The curriculum includes no less than 36 weeks ( 1440 hours) of APPE. All students are exposed to a minimum of 160 hours in each required APPE area. The majority of APPE is focused on direct patient care.

13.5. Timing - APPEs follow successful completion of all IPPE and required didactic curricular content. Required capstone courses or activities that provide opportunity for additional professional growth and insight are allowed during or after completion of APPEs. These activities do not compromise the quality of the APPEs, nor count toward the required 1440 hours of APPE.

13.6. Required APPE - Required APPEs occur in four practice settings: (1) community pharmacy; (2) ambulatory patient care; (3) hospital/health system pharmacy; and (4) inpatient general medicine patient care.

13.7. Elective APPE - Elective APPEs are structured to give students the opportunity to: (1) mature professionally, (2) secure the breadth and depth of experiences needed to 
achieve the Educational Outcomes articulated in Standards 1-4, and (3) explore various sectors of practice.

13.8. Geographic restrictions - Required APPEs are completed in the United States or its territories or possessions. All quality assurance expectations for U.S.-based

experiential education courses apply to elective APPEs offered outside of the U.S.

\section{Subsection IIC: Students}

\section{Standard 14: Student Services}

The college or school has an appropriately staffed and resourced organizational element dedicated to providing a comprehensive range of services that promote student success and well-being.

\section{Key Elements:}

14.1. FERPA - The college or school has an ordered, accurate, and secure system of student records in compliance with the Family Educational Rights and Privacy Act (FERPA). Student services personnel and faculty are knowledgeable regarding FERPA law and its practices.

14.2. Financial aid - The college or school provides students with financial aid information and guidance by appropriately trained personnel.

14.3. Healthcare - The college or school offers students access to adequate health and counseling services. Appropriate immunization standards are established, along with the means to ensure that such standards are satisfied.

14.4. Advising - The college or school provides academic advising, curricular and career-pathway counseling, and information on post-graduate education and training opportunities adequate to meet the needs of its students.

14.5. Nondiscrimination - The college or school establishes and implements student service policies that ensure nondiscrimination as defined by state and federal laws and regulations.

14.6. Disability accommodation - The college or school provides accommodations to students with documented disabilities that are determined by the university Disability Office (or equivalent) to be reasonable, and provides support to faculty in accommodating disabled students.

14.7. Student services access ${ }^{\star}$ - The college or school offering multiple professional degree programs (e.g., PharmD/MPH) or pathways (campus and distance pathways) ensures that all students have equitable access to a comparable system of individualized student services (e.g., tutorial support, faculty advising, counseling, etc.).

\section{Standard 15: Academic Environment}

The college or school develops, implements, and assesses its policies and procedures that promote student success and well-being. 


\section{Key elements:}

15.1. Student information - The college or school produces and makes available to enrolled and prospective students updated information of importance, such as governance documents, policies and procedures, handbooks, and catalogs.

15.2. Complaints policy - The college or school develops, implements, and makes available to students a complaints policy that includes procedures for how students may file complaints within the college or school and also directly to ACPE regarding their college or school's adherence to ACPE standards. The college or school maintains a chronological record of such student complaints, including how each complaint was resolved.

15.3. Student misconduct - The college or school develops and implements policies regarding academic and non-academic misconduct of students that clearly outline the rights and responsibilities of, and ensures due process for, all parties involved.

15.4. Student representation - The college or school considers student perspectives and includes student representation, where appropriate, on committees, in policydevelopment bodies, and in assessment and evaluation activities.

15.5. Distance learning policies* - For colleges and schools offering distance learning opportunities, admissions information clearly explains the conditions and requirements related to distance learning, including full disclosure of any requirements that cannot be completed at a distance.

\section{Standard 16: Admissions}

The college or school develops, implements, and assesses its admission criteria, policies, and procedures to ensure the selection of a qualified and diverse student body into the professional degree program.

\section{Key elements:}

16.1. Enrollment management - Student enrollment is managed by college or school administration. Enrollments are in alignment with available physical, educational, financial, faculty, staff, practice site, preceptor, and administrative resources.

16.2. Admission procedures - A duly constituted committee of the college or school has the responsibility and authority for the selection of students to be offered admission. Admission criteria, policies, and procedures are not compromised regardless of the size or quality of the applicant pool.

16.3. Program description and quality indicators - The college or school produces and makes available to the public, including prospective students: (1) a complete and accurate description of the professional degree program; (2) the program's current accreditation status; and (3) ACPE-required program performance information including on-time graduation rates and most recent NAPLEX first-attempt pass rates.

16.4. Admission criteria - The college or school sets performance expectations for admission tests, evaluations, and interviews used in selecting students who have the potential for success in the professional degree program and the profession. Applicant 
performance on admission criteria is documented; and the related records are maintained by the college or school as per program/university requirements.

16.5. Admission materials - The college or school produces and makes available to prospective students the criteria, policies, and procedures for admission to the professional degree program. Admission materials clearly state academic expectations, required communication skills, types of personal history disclosures that may be required, and professional and technical standards for graduation.

16.6. Written and oral communication assessment - Written and oral communication skills are assessed in a standardized manner as part of the admission process.

16.7. Candidate interviews - Standardized interviews (in-person, telephonic, and/or computer-facilitated) of applicants are conducted as a part of the admission process to assess affective domain characteristics (i.e., the Personal and Professional Development domain articulated in Standard 4).

16.8. Transfer and waiver policies - A college or school offering multiple professional degree programs, or accepting transfer students from other schools or colleges of pharmacy, establishes and implements policies and procedures for students who request to transfer credits between programs. Such policies and procedures are based on defensible assessments of course equivalency. A college or school offering multiple pathways to a single degree has policies and procedures for students who wish to change from one pathway to another.

\section{Standard 17: Progression}

The college or school develops, implements, and assesses its policies and procedures related to student progression through the PharmD program.

\section{Key elements:}

17.1. Progression policies - The college or school creates, makes available to students and prospective students, and abides by criteria, policies, and procedures related to:

- Academic progression

- Remediation

- Missed course work or credit

- Academic probation

- Academic dismissal

- Dismissal for reasons of misconduct

- Readmission

- Leaves of absence

- Rights to due process

- Appeal mechanisms (including grade appeals)

17.2. Early intervention - The college or school's system of monitoring student performance provides for early detection of academic and behavioral issues. The college or school develops and implements appropriate interventions that have the potential for successful resolution of the identified issues. 


\section{Subsection IID: Resources}

\section{Standard 18: Faculty and Staff-Quantitative Factors}

The college or school has a cohort of faculty and staff with the qualifications and experience needed to effectively deliver and evaluate the professional degree program.

\section{Key Elements:}

18.1. Sufficient faculty - The college or school has a sufficient number of faculty members to effectively address the following programmatic needs:

- Teaching (didactic, simulation, and experiential)

- Professional development

- Research and other scholarly activities

- Assessment activities

- College/school and/or university service

- Intraprofessional and interprofessional collaboration

- Student advising and career counseling

- Faculty mentoring

- Professional service

- Community service

- Pharmacy practice

- Responsibilities in other academic programs (if applicable)

- Support of distance students and campus(es) (if applicable)*

18.2. Sufficient staff - The college or school has a sufficient number of staff to effectively address the following programmatic needs:

- Student and academic affairs-related services, including recruitment and admission

- Experiential education

- Assessment activities

- Research administration

- Laboratory maintenance

- Information technology infrastructure

- Pedagogical and educational technology support

- Teaching assistance

- General faculty and administration clerical support

- Support of distance students and campus(es) (if applicable)*

\section{Standard 19: Faculty and Staff-Qualitative Factors}

Faculty and staff have academic and professional credentials and expertise commensurate with their responsibilities to the professional program and their academic rank. 


\section{Key Elements:}

19.1. Educational effectiveness - Faculty members have the capability and demonstrate a continuous commitment to be effective educators and are able to effectively use contemporary educational techniques to promote student learning in all offered pathways.

19.2. Scholarly productivity - The college or school creates an environment that both requires and promotes scholarship and also develops mechanisms to assess both the quantity and quality of faculty scholarly productivity.

19.3. Service commitment - In the aggregate, faculty engage in professional, institutional, and community service that advances the program and the profession of pharmacy.

19.4. Practice understanding - Faculty members, regardless of their discipline, have a conceptual understanding of and commitment to advancing current and proposed future pharmacy practice.

19.5. Faculty/staff development - The college or school provides opportunities for career and professional development of its faculty and staff, individually and collectively, to enhance their role-related skills, scholarly productivity, and leadership.

19.6. Policy application - The college or school ensures that policies and procedures for faculty and staff recruitment, performance review, promotion, tenure (if applicable), and retention are applied in a consistent manner.

\section{Standards 20: Preceptors}

The college or school has a sufficient number of preceptors (practice faculty or external practitioners) to effectively deliver and evaluate students in the experiential component of the curriculum. Preceptors have professional credentials and expertise commensurate with their responsibilities to the professional program.

\section{Key Elements:}

20.1. Preceptor criteria - The college or school makes available and applies quality criteria for preceptor recruitment, orientation, performance, and evaluation. The majority of preceptors for any given student are U.S. licensed pharmacists.

20.2. Student-to-preceptor ratio - Student to precepting pharmacist ratios allow for the individualized mentoring and targeted professional development of learners.

20.3. Preceptor education and development - Preceptors are oriented to the program's mission, the specific learning expectations for the experience outlined in the syllabus, and effective performance evaluation techniques before accepting students. The college or school fosters the professional development of its preceptors commensurate with their educational responsibilities to the program. 
20.4. Preceptor engagement - The college or school solicits the active involvement of preceptors in the continuous quality improvement of the educational program, especially the experiential component.

20.5. Experiential education administration - The experiential education component of the curriculum is led by a pharmacy professional with knowledge and experience in experiential learning. The experiential education program is supported by an appropriate number of qualified faculty and staff.

\section{Standard 21: Physical Facilities and Educational Resources}

The college or school has adequate and appropriately equipped physical and educational facilities to achieve its mission and goals.

\section{Key Elements:}

21.1. Physical facilities - The college or school's physical facilities (or the access to other facilities) meet legal and safety standards, utilize current educational technology, and are clean and well maintained.

21.2. Physical facilities' attributes - The college or school's physical facilities also include adequate:

- Faculty office space with sufficient privacy to permit accomplishment of responsibilities

- Space that facilitates interaction of administrators, faculty, students, and interprofessional collaborators

- Classrooms that comfortably accommodate the student body and that are equipped to allow for the use of required technology

- Laboratories suitable for skills practice, demonstration, and competency evaluation

- Access to educational simulation capabilities

- Faculty research laboratories with well-maintained equipment including research support services within the college or school and the university

- Animal facilities that meet care regulations (if applicable)

- Individual and group student study space and student meeting facilities

21.3. Educational resource access - The college or school makes available technological access to current scientific literature and other academic and educational resources by students, faculty, and preceptors.

21.4 Librarian expertise access - The college or school has access to librarian resources with the expertise needed to work with students, faculty, and preceptors on effective literature and database search and retrieval strategies.

\section{Standard 22: Practice Facilities}

The college or school has the appropriate number and mix of facilities in which required and elective practice experiences are conducted to accommodate all students. Practice sites are appropriately licensed and selected based on quality criteria to ensure the effective and timely delivery of the experiential component of the curriculum. 


\section{Key Elements:}

22.1. Quality criteria - The college or school employs quality criteria for practice facility recruitment and selection, as well as setting forth expectations and evaluation based on student opportunity to achieve the required Educational Outcomes as articulated in Standards 1-4.

22.2. Affiliation agreements - The college or school secures and maintains signed affiliation agreements with the practice facilities it utilizes for the experiential component of the curriculum. At a minimum, each affiliation agreement ensures that all experiences are conducted in accordance with state and federal laws.

22.3. Evaluation - Practice sites are regularly evaluated. Quality enhancement initiatives and processes are established, as needed, to improve student learning outcomes.

\section{Standard 23: Financial Resources}

The college or school has current and anticipated financial resources to support the stability of the educational program and accomplish its mission, goals, and strategic plan.

\section{Key Elements:}

23.1. Enrollment support - The college or school ensures that student enrollment is commensurate with resources.

23.2. Budgetary input - The college or school provides input into the development and operation of a budget that is planned, executed, and managed in accordance with sound and accepted business practices.

23.3. Revenue allocation - Tuition and fees for pharmacy students are not increased to support other educational programs if it compromises the quality of the professional program.

23.4. Equitable allocation - The college or school ensures that funds are sufficient to maintain equitable facilities (commensurate with services and activities) across all program pathways. 


\section{SECTION III: ASSESSMENT OF STANDARDS AND KEY ELEMENTS}

In the spirit of continuous quality improvement and transparency, colleges and schools evaluate and report to constituents the extent to which they meet their programmatic goals. Insights gained from the valid and reliable assessment of outcomes related to mission, strategic planning, educational programs, and other key institutional initiatives are channeled into constructive change to enhance programmatic quality.

\section{Standard 24: Assessment Elements for Section I: Educational Outcomes}

The college or school develops, resources, and implements a plan to assess attainment of educational outcomes to ensure that graduates are prepared to enter practice.

\section{Key Elements:}

24.1. Formative and summative assessment - The assessment plan incorporates systematic, valid, and reliable knowledge-based and performance-based formative and summative assessments.

24.2. Standardized and comparative assessments - The assessment plan includes standardized assessments as required by ACPE (see Appendix 3) that allow for national comparisons and college- or school-determined peer comparisons.

24.3. Student achievement and readiness - The assessment plan measures student achievement at defined levels of the professional competencies that support attainment of the Educational Outcomes in aggregate and at the individual student level. In addition to college/school desired assessments, the plan includes an assessment of student readiness to:

- Enter advanced pharmacy practice experiences

- Provide direct patient care in a variety of healthcare settings

- Contribute as a member of an interprofessional collaborative patient care team

24.4. Continuous improvement - The college or school uses the analysis of assessment measures to improve student learning and the level of achievement of the Educational Outcomes.

\section{Standard 25: Assessment Elements for Section II: Structure and Process}

The college or school develops, resources, and implements a plan to assess attainment of the Key Elements within Standards 5-23.

\section{Specific Key Elements:}

25.1. Assessment of organizational effectiveness - The college or school's assessment plan is designed to provide insight into the effectiveness of the organizational structure in engaging and uniting constituents and positioning the college or school for success through purposeful planning. 
25.2. Program evaluation by stakeholders - The assessment plan includes the use of data from AACP standardized surveys of graduating students, faculty, preceptors, and alumni.

25.3. Curriculum assessment and improvement - The college or school systematically assesses its curricular structure, content, organization, and outcomes. The college or school documents the use of assessment data for continuous improvement of the curriculum and its delivery.

25.4. Faculty productivity assessment - The college or school systematically assesses the productivity of its faculty in scholarship, teaching effectiveness, and professional and community service.

25.5. Pathway comparability* - The assessment plan includes a variety of assessments that will allow comparison and establishment of educational parity of alternative program pathways to degree completion, including geographically dispersed campuses and online or distance learning-based programs.

25.6. Interprofessional preparedness - The college or school assesses the preparedness of all students to function effectively and professionally on an interprofessional healthcare team.

25.7. Clinical reasoning skills - Evidence-based clinical reasoning skills, the ability to apply these skills across the patient's lifespan, and the retention of knowledge that underpins these skills, are regularly assessed throughout the curriculum.

25.8. APPE preparedness - The Pre-APPE curriculum leads to a defined level of competence in professional knowledge, knowledge application, patient and populationbased care, medication therapy management skills, and the attitudes important to success in the advanced experiential program. Competence in these areas is assessed prior to the first APPE.

25.9. Admission criteria - The college or school regularly assesses the criteria, policies, and procedures to ensure the selection of a qualified and diverse student body, members of which have the potential for academic success and the ability to practice in team-centered and culturally diverse environments. 


\section{Appendix 1 \\ Required Elements of the Didactic Doctor of Pharmacy Curriculum ${ }^{4}$}

The following didactic content areas and associated learning expectations are viewed as central to a contemporary, high-quality pharmacy education and are incorporated at an appropriate breadth and depth in the required didactic Doctor of Pharmacy curriculum. Where noted, content areas may be addressed in the pre-professional curriculum (i.e., as requirements for admission). Required content areas may be delivered within individual or integrated courses, and may involve multiple disciplines.

This appendix was purposely written at the level of broad learning outcomes. It was constructed to provide statements of concepts and understandings essential for pharmacists to master, rather than a list of required topics to cover in the didactic curriculum. The goal is to ensure that critical areas of learning are included in the curricula of all programs without dictating how the lessons are structured, organized, or delivered.

The clear expectation embedded within Appendix 1 is that students will develop the comprehensive knowledge base required to be 'practice ready' and that they will be able to retain, recall, build upon, and apply that knowledge to deliver quality patient care in a variety of entry-level practice settings.

NOTE: The topics under each Science category are organized in alphabetical order.

Biomedical Sciences (may be addressed in the pre-professional curriculum)

\section{Biochemistry}

- $\quad$ Structure, properties, biological functions, applicable kinetics, and metabolic fate of macromolecules essential to life (proteins, lipids, carbohydrates, and nucleic acids). Application of these concepts to identify endogenous targets for drug therapy and rational drug design strategies.

\section{Biostatistics}

- Appropriate use of commonly employed statistical tests, management of data sets, and the evaluation of the validity of conclusions generated based on the application of those tests to the data sets.

Human Anatomy

- $\quad$ Structure of major human body systems at the cellular, tissue, organ, and system level.

\section{Human Physiology}

- Homeostatic function and normal response reactions across the lifespan of nondiseased human cells, organs, and systems.

$\underline{\text { Immunology }}$

- Human immune system components, innate and adaptive immune responses to infection, injury and disease, and augmentation of the human immune system to prevent disease.

\footnotetext{
${ }^{4}$ Revised Appendix B from Standards 2007.
} 
Medical Microbiology

- Structure, function, and properties of microorganisms (bacteria, viruses, parasites, and fungi) responsible for human disease, and rational approaches to their containment or eradication.

Pathology/Pathophysiology

- Basic principles, mechanisms, functional changes and metabolic sequelae of human disease impacting cells, organs, and systems.

\section{Pharmaceutical Sciences}

Clinical Chemistry

- Application of clinical laboratory data to disease state management, including screening, diagnosis, progression, and treatment evaluation.

\section{Extemporaneous Compounding}

- Preparation of sterile and non-sterile prescriptions which are pharmaceutically accurate regarding drug product and dose, free from contamination, and appropriately formulated for safe and effective patient use. Analysis of the scientific principles and quality standards upon which these compounding requirements are based.

\section{Medicinal Chemistry}

- Chemical basis of drug action and behavior in vivo and in vitro, with an emphasis on pharmacophore recognition and the application of physicochemical properties, structureactivity relationships, intermolecular drug-receptor interactions and metabolism to therapeutic decision-making.

\section{Pharmaceutical Calculations}

- Mastery of mathematical skills required to accurately prepare prescriptions (including extemporaneously compounded dosage forms) that are therapeutically sound and safe for patient use. Calculation of patient-specific nutritional and drug dosing/delivery requirements.

\section{Pharmaceutics/Biopharmaceutics}

- Physicochemical properties of drugs, excipients, and dosage forms important to the rational design and manufacture of sterile and non-sterile products. Application of physical chemistry and dosage form science to drug stability, delivery, release, disposition, pharmacokinetics, therapeutic effectiveness, and the development of quality standards for drug products.

\section{Pharmacogenomics/genetics}

- Genetic basis for disease and individual differences in metabolizing enzymes, transporters, and other biochemicals impacting drug disposition and action that underpin the practice of personalized medicine. 


\section{Pharmacokinetics}

- Mathematical determination of the rate of drug movement from one therapeutic or physiologic compartment to another. Application of physicochemical and kinetic principles and parameters to therapeutically important issues, such as drug delivery, disposition, therapeutic effectiveness, and beneficial or adverse interactions in general and specific populations.

\section{Pharmacology}

- Pharmacodynamics, mechanisms of therapeutic and adverse drug actions and interactions, lifespan-dependent variations in physiology or biochemistry that impact drug action and effectiveness, and application of these principles to therapeutic decisionmaking.

Toxicology

- Pharmacodynamics, mechanisms, prevention, and treatment of the toxic effects of drugs and poisons, including poisons associated with bioterrorism.

\section{Social/Administrative/Behavioral Sciences}

\section{Cultural Awareness}

- Exploration of the potential impact of cultural values, beliefs, and practices on patient care outcomes.

\section{Ethics}

- Exploration of approaches for resolving ethical dilemmas in patient care, with an emphasis on moral responsibility and the ability to critically evaluate viable options against the needs of patients and other key stakeholders.

\section{Healthcare Systems}

- Examination of U.S. health systems and contemporary reimbursement models in which patient-centered and/or population-based care is provided and paid for, and how social, political, economic, organizational, and cultural factors influence providers' ability to ensure patient safety and deliver coordinated interprofessional care services.

\section{History of Pharmacy}

- Exploration of the evolution of pharmacy as a distinct profession, the transition from a focus on the drug to a focus on the patient and the drug (including pharmacist-provided patient care), and major milestones and contributors in the evolution of pharmacy.

\section{Pharmacoeconomics}

- Application of economic principles and theories to the provision of cost-effective pharmacy products and services that optimize patient-care outcomes, particularly in situations where healthcare resources are limited.

\section{Pharmacoepidemiology}

- Cause-and-effect patterns of health and disease in large populations that advance safe and effective drug use and positive care outcomes within those populations. 


\section{Pharmacy Law and Regulatory Affairs}

- Federal and appropriate state-specific statutes, regulations, policies, executive orders, and court decisions that regulate the practice of pharmacy, including the mitigation of prescription drug abuse and diversion.

\section{Practice Management}

- Application of sound management principles (including operations, information, resource, fiscal, and personnel) and quality metrics to advance patient care and service delivery within and between various practice settings.

\section{Professional Communication}

- Analysis and practice of verbal, non-verbal, and written communication strategies that promote effective interpersonal dialog and understanding to advance specific patient care, education, advocacy, and/or interprofessional collaboration goals. Exploration of technology-based communication tools and their impact on healthcare delivery, healthcare information, and patient empowerment.

\section{Professional Development/Social and Behavioral Aspects of Practice}

- Development of professional self-awareness, capabilities, responsibilities, and leadership. Analysis of contemporary practice roles and innovative opportunities, and inculcation of professional attitudes, behaviors, and dispositions.

\section{Research Design}

- Evaluation of research methods and protocol design required to conduct valid and reliable studies to test hypotheses or answer research questions, and to appropriately evaluate the validity and reliability of the conclusions of published research studies.

\section{Clinical Sciences}

\section{Clinical Pharmacokinetics}

- Application of basic pharmacokinetic principles and mathematical models to calculate safe and effective doses of drugs for individual patients, and adjust therapy as appropriate through the monitoring of drug concentration in biological fluids.

Health Informatics

- Effective and secure design and use of electronic and other technology-based systems, including electronic health records, to capture, store, retrieve, and analyze data for use in patient care, and confidentially/legally share health information in accordance with federal policies.

Health Information Retrieval and Evaluation

- Critical analysis and application of relevant health sciences literature and other information resources to answer specific patient-care and/or drug-related questions and provide evidence-based therapeutic recommendations to healthcare providers or, when appropriate, the public.

Medication Dispensing, Distribution and Administration

- Preparation, dispensing and administration of prescriptions, identification and prevention of medication errors and interactions, maintaining and using patient profile systems and 
prescription processing technology and/or equipment, and ensuring patient safety. Educating about appropriate medication use and administration.

\section{$\underline{\text { Natural Products and Alternative and Complementary Therapies }}$}

- Evidence-based evaluation of the therapeutic value, safety, and regulation of pharmacologically active natural products and dietary supplements. Cultural practices commonly selected by practitioners and/or patients for use in the promotion of health and wellness, and their potential impact on pharmacotherapy.

\section{Patient Assessment}

- Evaluation of patient function and dysfunction through the performance of tests and assessments leading to objective (e.g., physical assessment, health screening, and lab data interpretation) and subjective (patient interview) data important to the provision of care.

\section{Patient Safety}

- Analysis of the systems- and human-associated causes of medication errors, exploration of strategies designed to reduce/eliminate them, and evaluation of available and evolving error-reporting mechanisms.

\section{Pharmacotherapy}

- Evidence-based clinical decision making, therapeutic treatment planning, and medication therapy management strategy development for patients with specific diseases and conditions that complicate care and/or put patients at high risk for adverse events. Emphasis on patient safety, clinical efficacy, pharmacogenomic and pharmacoeconomic considerations, and treatment of patients across the lifespan.

\section{Public Health}

- Exploration of population health management strategies, national and community-based public health programs, and implementation of activities that advance public health and wellness, as well as provide an avenue through which students earn certificates in immunization delivery and other public health-focused skills.

\section{Self-Care Pharmacotherapy}

- Therapeutic needs assessment, including the need for triage to other health professionals, drug product recommendation/selection, and counseling of patients on non-prescription drug products, non-pharmacologic treatments and health/wellness strategies. 


\section{Appendix 2 \\ Expectations within the \\ APPE Curriculum}

Builds on IPPE. APPE follows IPPE, which is designed to progressively develop the professional insights and skills necessary to advance into responsibilities in APPE. Colleges and schools use a variety of IPPE delivery mechanisms to ensure students are ready to meet the expectations of APPE. IPPE involves interaction with practitioners and patients to advance patient welfare in authentic practice settings, and provides exposure to both medication distribution systems and high-quality, interprofessional, team-based patient care.

APPE curriculum. APPE ensures that students have multiple opportunities to perform patientcentered care and other activities in a variety of settings. Experiences are in-depth, structured, and comprehensive in the aggregate, and carefully coordinated with other components of the PharmD curriculum. Collectively, APPE hones the practice skills, professional judgment, behaviors, attitudes and values, confidence, and sense of personal and professional responsibility required for each student to practice independently and collaboratively in an interprofessional, team-based care environment.

Learning outcomes. General and experience-specific learning outcomes are established for all APPEs. Learning outcomes identify the competencies to be achieved, expected patient populations (if applicable), level of student responsibility, and the setting needed for the outcomes to be met. Learning outcomes for each experience are mapped to the professional practice competencies outlined in the Standards, as well as to any additional competencies developed by the school or college.

Assessment. Colleges and schools assess student achievement of APPE competencies within their assessment plans using reliable, validated assessments. Formative feedback related to specific performance criteria is provided to students throughout the experience. At a minimum, performance competence is documented midway through the experience and at its completion.

Learning activities. The APPE curriculum, in the aggregate, includes but is not limited to: (1) direct patient care, (2) interprofessional interaction and practice, (3) medication dispensing, distribution, administration, and systems management, and (4) professional development. Examples of possible activities within these broad areas are listed in the Guidance document.

Interprofessional interaction. The need for interprofessional interaction is paramount to successful treatment of patients. Colleges and schools provide pharmacy students the opportunity to gain interprofessional skills using a variety of mechanisms including face-to-face interactions in clinical settings or in real-time telephonic or video-linked interactions. Regardless of the methods used, students demonstrate those interprofessional skills articulated in Standard 11.

Direct patient care focus. The majority of student time in APPE is focused on the provision of direct patient care to both inpatients and outpatients. APPE is of sufficient length to permit continuity of care of individual patients and documentation of achievement of competencies associated with the APPE curriculum.

Practice settings. Students demonstrate competence within four main practice types: community, ambulatory care, general medicine, and health system pharmacy. Colleges and 
schools draft competency statements for each type of setting along with appropriate assessment plans.

Ambulatory care. Ambulatory care pharmacy practice is the provision of integrated, accessible health care services by pharmacists who are accountable for addressing medication needs, developing sustained partnerships with patients, and practicing in the context of family and community. ${ }^{5}$ The ambulatory care setting involves interprofessional communication and collaboration to provide acute and chronic patient care that can be accomplished outside the inpatient setting.

Blended environments. The literature documents that the demarcations between various types of pharmacy practice are blurring. A specific APPE may involve skill-development activities in more than one of the four required practice settings (i.e., the 'blending' of two or more of the four required practice types within one APPE). In addition, 'Iongitudinal' experiences may exist where students participate in more than one of the four required APPEs within the same institution (i.e., taking a general medicine APPE, an ambulatory care APPE, and a health system pharmacy APPE in the same hospital). The key is that a college or school documents how its APPE program is balanced between the four required practice areas and how all program outcomes, student performance competencies, and ACPE standards are met.

Elective APPE. Elective rotations allow students to explore areas of professional interest and/or expand their understanding of professional opportunities. Elective APPE may include a maximum of two experiences without a patient care focus.

\footnotetext{
${ }^{5}$ www.bpsweb.org/specialties/AmbulatoryCarePharmacy.cfm
} 


\section{Appendix 3 \\ Required Documentation for \\ Standards and Key Elements 2016}

To provide evidence of achievement of the standards and key elements, colleges and schools provide, at a minimum, the following outcomes data and documentation. Many of these documents are embedded within the Assessment and Accreditation Management System (AAMS) system (co-developed and managed by the American Association of Colleges of Pharmacy and ACPE), while others are created by individual colleges and schools to be shared with ACPE at appropriate times during the quality improvement process (e.g., within self-study submissions or during site visits). As noted below, an individual document may be used for multiple standards. Colleges and schools are encouraged to develop additional documentation processes to meet their mission-specific quality assurance needs.

\section{Standard 1 - Foundational Knowledge}

- Student academic performance throughout the program (e.g., progression rates, academic probation rates, attrition rates)

- Annual performance of students nearing completion of the didactic curriculum on the Pharmacy Curriculum Outcomes Assessment (PCOA) - an assessment of knowledge of the essential content areas identified in Appendix 1

- Performance of graduates (passing rate) on NAPLEX

- Performance of graduates in the various NAPLEX competency areas

- Performance of graduates on Multistate Pharmacy Jurisprudence Examination (MPJE) and/or other state required law examination

Standard 2 - Essentials for Practice and Care

- Outcome data from assessments summarizing overall student achievement of relevant didactic, IPPE, and APPE learning objectives

\section{Standard 3 - Approach to Practice and Care}

- Examples of student participation in Interprofessional Education activities (didactic, simulation, experiential)

- Outcome data from assessments summarizing overall student achievement of relevant didactic, IPPE, and APPE learning objectives

- Outcome data from assessments summarizing overall student participation in Interprofessional Education activities

- Examples of curricular and co-curricular experiences made available to students to document developing competence in affective domain-related expectations of Standard 3

- Outcome data from assessments of student achievement of problem-solving and critical thinking capabilities

- Outcome data from assessments of students' ability to communicate professionally, advocate for patients, and educate others

- Outcome data from assessments of students' demonstration of cultural awareness and sensitivity.

\section{Standard 4 - Personal and Professional Development}

- Outcome data from assessments summarizing students' overall achievement of relevant didactic, IPPE, and APPE learning objectives

- Examples of curricular and co-curricular experiences made available to students to document developing competence in affective domain-related expectations of Standard 4 
- Outcome data from assessments summarizing students' overall achievement of professionalism, leadership, self-awareness, and creative thinking expectations

- Description of tools utilized to capture students' reflections on personal/professional growth and development

- Description of processes by which students are guided to develop a commitment to continuous professional development and to self-directed lifelong learning

\section{Standard 5 - Eligibility and Reporting Requirements}

- Legal authority to offer/award the Doctor of Pharmacy degree

- Documents verifying institutional accreditation

- Accreditation reports identifying deficiencies (if applicable)

- University organizational chart

- Description of level of autonomy of the college or school

Standard 6 - College or School Vision, Mission, and Goals

- Vision, mission, and goal statements (college, school, parent institution, department/division)

- Outcome data from assessments summarizing the extent to which the college or school is achieving its vision, mission, and goals

Standard 7 - Strategic Plan

- Strategic planning documents, including a description of the process through which the strategic plan was developed.

- Outcome data from assessments summarizing the implementation of the strategic plan

Standard 8 - Organization and Governance

- Curriculum vitae of the dean and others on the administrative leadership team

- Organization chart of the college or school

- Responsibilities of dean and other administrative leadership team members

- Faculty governance documents (by-laws, policies, procedures, etc.)

- List of committees and designated charges

- Evidence of faculty participation in university governance

- Policies and procedures related to system failures, data security and backup, and contingency planning

- Outcome data from assessments (e.g., AACP faculty, preceptor, graduating student and alumni surveys) summarizing the effectiveness of the organizational structure and governance

\section{Standard 9 - Organizational Culture}

- Policies describing expectations of faculty, administrators, students, and staff behaviors

- Examples of intra/interprofessional and intra/interdisciplinary collaboration

- Affiliation agreements for purposes of research, teaching, or service (if applicable)

- Outcome data from AACP faculty and graduating student surveys related to collaboration, morale, professionalism, etc.

Standard 10 - Curriculum Design, Delivery, and Oversight

- Description of curricular and degree requirements, including elective didactic and experiential expectations

- All required and elective didactic and experiential course syllabi

- Mapping of required curricular content and experiential education expectations to individual courses

- Curriculum vitae of faculty teaching within the curriculum

- A tabular display of courses, faculty members assigned to each course and their role, and credentials supporting the teaching assignments 
- List of Curriculum Committee (or equivalent) members with position/affiliation within college/school

- List of charges, assignments, and accomplishments of Curriculum Committee over the last $1-3$ years

- Examples of tools (e.g., portfolios) used by students to document self-assessment of, and reflection on, learning needs, plans and achievements, and professional growth and development

- Sample documents used by faculty, preceptors, and students to evaluate learning experiences and provide formative and/or summative feedback

- Policies related to academic integrity

- Policies related to experiential learning that ensures compliance with Key Element 10.15

- Examples of instructional methods used by faculty and the extent of their employment to:

o Actively engage learners

o Integrate and reinforce content across the curriculum

o Provide opportunity for mastery of skills

0 Instruct within the experiential learning program

o Stimulate higher-order thinking, problem-solving, and clinical-reasoning skills

o Foster self-directed lifelong learning skills and attitudes

o Address/accommodate diverse learning styles

o Incorporate meaningful interprofessional learning opportunities

\section{Standard 11 - Interprofessional Education (IPE)}

- Vision, mission, and goal statements related to IPE

- Statements addressing IPE and practice contained within student handbooks and/or catalogs

- Relevant syllabi for required and elective didactic and experiential education courses that incorporate elements of IPE to document that concepts are reinforced throughout the curriculum and that IPE-related skills are practiced at appropriate times during preAPPE

- Student IPPE and APPE evaluation data documenting extent of exposure to interprofessional, team-based patient care

- Outcome data from assessments summarizing students' overall achievement of expected interprofessional educational outcomes in the pre-APPE and APPE curriculum

\section{Standard 12 - Pre-APPE Curriculum}

- Description of curricular and degree requirements, including elective didactic and experiential expectations

- A tabular display of courses, faculty members assigned to each course and their role, and credentials supporting the teaching assignments

- Curriculum maps documenting breadth and depth of coverage of Appendix 1 content and learning expectations in the professional (and, if appropriate, preprofessional) curriculum

- Examples of curricular and co-curricular experiences made available to students to document developing competence in affective domain-related expectations of Standards 3 and 4

- Outcome data from assessments of student preparedness to progress to APPE (e.g., comprehensive assessments of knowledge, skills, and competencies)

- Description of the IPPE learning program and its goals, objectives, and time requirements

- List of simulation activities and hours counted within the IPPE 300 hour requirement

- IPPE course syllabi including general and rotation-specific learning objectives and extent of IPE exposure 
- IPPE student and preceptor manuals

- IPPE student and preceptor assessment tools

- IPPE preceptor recruitment and training manuals and/or programs

- List of active preceptors with credentials and practice site

- Outcome data from assessments summarizing overall student achievement of PreAPPE educational outcomes

\section{Standard 13 - APPE Curriculum}

- Overview of APPE curriculum (duration, types of required and elective rotations, etc.)

- APPE course syllabi including general and experience-specific learning objectives

- APPE student and preceptor manuals

- APPE student and preceptor assessment tools

- Preceptor recruitment and training manuals and/or programs

- List of active preceptors with credentials and practice site

- Student APPE evaluation data documenting extent of exposure to diverse patient populations and interprofessional, team-based patient care

- Outcome data from assessments summarizing students' overall achievement of APPE educational outcomes

\section{Standard 14 - Student Services}

- Organizational chart depicting Student Services unit and responsible administrators

- Synopsis of curriculum vitae of Students Services administrative officer(s) and staff

- Student Handbook and/or Catalog (college, school or university), and copies of additional information distributed to students regarding student service elements (financial aid, health insurance, etc.)

- Copies of policies that ensure nondiscrimination and access to allowed disability accommodations

- Results from AACP graduating student survey

- Student feedback on the college/school's self-study

\section{Standard 15 - Academic Environment}

- Student Handbook and/or Catalog (college, school, or university), and copies of additional information distributed to students regarding the academic environment

- URL or link to program information on college or school's website

- Copy of student complaint policy related to college or school adherence to ACPE standards

- Number and nature of student complaints related to college or school adherence to ACPE standards (inspection of the file by evaluation teams during site visits)

- List of committees involving students with names and professional years of current student members

- College or school's code of conduct (or equivalent) addressing professional behavior

\section{Standard 16 - Admissions}

- Organizational chart depicting Admissions unit and responsible administrator(s)

- Enrollment data for the past five years by year; and by branch campus or pathway (if applicable)

- Enrollment projections for the next five years

- Pharmacy College Aptitude Test (PCAT) scores (mean, maximum, and minimum), if required, for the past three admitted classes

- GPA scores (mean, maximum, and minimum) for preprofessional coursework for the past three admitted classes

- GPA scores (mean, maximum, and minimum) for preprofessional science courses for the past three admitted classes 
- Comparisons of PCAT scores and preprofessional GPAs with peer schools for last admitted three admitted classes

- List of admission committee members with name and affiliation

- Policies and procedures regarding the admissions process including selection of admitted students, transfer of credit, and course waiver policies

- Professional and technical standards for school, college, and/or university (if applicable)

- List of preprofessional requirements for admission into the professional program

- Copies of instruments used during the admissions process including interview evaluation forms and assessment of written and oral communication

- Section of Student Handbook and/or Catalog (college, school, or university) regarding admissions

- Link to websites (or documentation of other mechanisms) that provide to the public information on required indicators of quality

\section{Standard 17 - Progression}

- Policies and procedures regarding student progression, early intervention, academic probation, remediation, missed course work or credit, leaves of absence, dismissal, readmission, due process, and appeals

- Section of Student Handbook and/or Catalog (college, school, or university) regarding student progression

- Student progression and academic dismissal data for the last three admitted classes

- Correlation analysis of admission variables and academic performance

\section{Standard 18 - Faculty and Staff - Quantitative Factors}

- Organizational chart depicting all full-time faculty by department/division

- List of full-time staff in each department/division and areas of responsibility

- ACPE documents (e.g., resource report) related to number of full-time and part-time faculty

- List of faculty turnover for the past five years by department/division with reasons for departure

- Description of coursework mapped to full-time and part-time faculty teaching in each course

- Results from AACP faculty survey regarding adequacy of quantitative strength of faculty and staff

\section{Standard 19 - Faculty and Staff - Qualitative Factors}

- Curriculum vitae of faculty and professional staff

- List of active research areas of faculty and an aggregate summary of faculty publications/presentations over the past three years.

- Procedures employed to promote a conceptual understanding of contemporary practice, particularly among non-pharmacist faculty

- Policies and procedures related to faculty recruitment, performance review, promotion, tenure (if applicable), and retention

- Faculty Handbook

- Data from AACP faculty survey regarding qualitative faculty factors

\section{Standard 20 - Preceptors}

- List of active preceptors with credentials and practice site

- Number, percentage of required APPE precepted by non-pharmacists categorized by type of experience.

- Description of practice sites (location, type of practice, student/preceptor ratios)

- Policies and procedures related to preceptor recruitment, orientation, development, performance review, promotion, and retention 
- Examples of instruments used by preceptors to assess student performance

- Curriculum vitae of administrator(s) responsible for overseeing the experiential education component of the curriculum

- Description of the structure, organization and administrative support of the Experiential Education office (or equivalent)

- Results from AACP preceptor surveys

Standard 21 - Physical Facilities and Educational Resources

- Floor plans for college or school's facilities and descriptions of the use(s) of available space

- Description of shared space and how such space promotes interprofessional interaction

- Analysis of the quantity and quality of space available to the program and plans to address identified inadequacies.

- Documentation of Association for Assessment and Accreditation of Laboratory Animal Care (AAALAC) or other nationally recognized accreditation of animal care facilities, if applicable

- Results from AACP faculty, alumni, and graduating student surveys related to facilities

- Description of educational resources available to faculty, preceptors, and students (library, internet access, etc.)

Standard 22 - Practice Facilities

- Description of practice sites (location, type of practice, student:preceptor ratios) and involvement in IPPE, APPE, or both

- Policies and procedures related to site selection, recruitment, and assessment

- Examples of quality improvements made to improve student learning outcomes as a result of site/facility assessment

- Examples of affiliation agreements between college/school and practice sites (all agreements will be reviewed during site visits)

- ACPE IPPE and APPE Capacity Charts

Standard 23 - Financial Resources

- Detailed budget plan as defined by AACP (previous, current, and subsequent years)

- Description of college or school's budgetary processes

- In-state and out-of-state tuition compared to peer schools

- Results from AACP faculty survey regarding adequacy of financial resources

Standard 24 - Assessment Elements for Section I

- College or school's curriculum assessment plan(s)

- Description of formative and summative assessments of student learning and professional development used by college or school

- Description of standardized and comparative assessments of student learning and professional development used by college or school

- Description of how the college or school uses information generated within the curriculum assessment plan(s) to advance quality within its Doctor of Pharmacy program

\section{Standard 25 - Assessment Elements for Section II}

- College or school's program assessment plan(s)

- Description of how the college or school uses information generated by assessments related to its organizational effectiveness, mission and goals, didactic curriculum, experiential learning program, co-curriculum activities, and interprofessional education to advance overall programmatic quality 